\title{
Quantifying spatiotemporal pattern of urban greenspace: new insights from high resolution data
}

\author{
Yuguo Qian • Weiqi Zhou • Wenjuan Yu • \\ Steward T. A. Pickett
}

Received: 6 January 2015/Accepted: 30 March 2015/Published online: 16 April 2015

(C) Springer Science+Business Media Dordrecht 2015

\begin{abstract}
Context Urban greenspace provides myriad ecosystem services. To fully understand the ecological services provided by urban greenspace, it is crucial to first accurately quantify the composition and configuration, and change of urban greenspace.

Objectives (1) Quantify the dynamics of greenspace in highly urbanized areas. (2) Compare and evaluate the efficacy of medium and high resolution image data on quantifying urban greenspace dynamics.

Methods Using two very well-developed urban districts of Beijing, we compare and contrast the changes in urban greenspace from 2005 to 2009 based on two different datasets, the most commonly used Landsat TM data with $30 \mathrm{~m}$ resolution, and $2.5 \mathrm{~m}$ high spatial resolution imagery.
\end{abstract}

Y. Qian · W. Zhou $(\bowtie) \cdot$ W. Yu

State Key Laboratory of Urban and Regional Ecology, Research Center for Eco-Environmental Sciences, Chinese Academy of Sciences, Shuangqinglu 18,

Beijing 100085, China

e-mail:wzhou@rcees.ac.cn

Y. Qian

e-mail: guozigu1015@163.com

W. Yu

e-mail: yuwenjuan_1986@163.com

S. T. A. Pickett

Cary Institute of Ecosystem Studies, Box AB,

Millbrook, NY 12545, USA

e-mail: picketts@caryinstitute.org
Results We found urban greenspace in the two welldeveloped urban districts of Beijing to be very dynamic, in contrast to findings from previous research that greenspace in inner cities tends to remain largely unchanged. Such dynamics, however, could only be revealed by high spatial resolution imagery because medium resolution data, such as TM data greatly underestimated the percent cover of greenspace. The underestimate neglects smaller elements of greenspace as well as changes in configuration of larger patches, limiting the ability of TM data to detect such changes. Conclusions Our results underscore the importance and necessity of using high spatial resolution data to adequately quantify the distribution of urban greenspace and its change. Results from this study have important implications for urban greenspace management and planning. In addition, the dynamics revealed support emerging conceptions of urban areas as hierarchical patch mosaics.

Keywords Within-city dynamics · Beijing - Urban sustainability $\cdot$ Ecosystem services $\cdot$ Scale $\cdot$ Urban landscape

\section{Introduction}

Urban greenspace is widely believed to provide myriad ecosystem services, which are crucial for urban sustainability (Wu 2010, 2013). These include regulation of climate and water cycles (Bolund and 
Hunhammar 1999; Zhou et al. 2011), noise reduction (Pathak et al. 2011), air pollution mitigation (Yang et al. 2005; Nowak et al. 2006), reduced energy use (Ng et al. 2012), increased property values (Tajima 2003), and improved aesthetics (Home et al. 2010). Presence of urban vegetation can also contribute to reductions in residents' stress and feelings of anger and anxiety (Thompson et al. 2012), and generate stronger social cohesion and community empowerment (Wolf and Housley 2014). To fully understand the ecosystem services provided by urban greenspace, it is crucial to first accurately characterize and quantify its spatiotemporal pattern at the appropriate scale (Lovell and Taylor 2013; Huang et al. 2014; Wu 2014; Zhou et al. 2014).

Urban greenspace is notoriously heterogeneous and highly fragmented, characterized by relatively rare large patches of greenspace, and abundant dispersed small patches of vegetation (Zhou et al. 2011; Wolch et al. 2014; Qian et al. 2015a). Quantification of spatiotemporal pattern of urban greenspace frequently relies on remote sensing. A variety of remotely sensed image data with different spatial resolutions, ranging from sub-meter to $1000 \mathrm{~m}$, can be used for urban greenspace mapping and change analysis (e.g., Stefanov et al. 2001; Zhang et al. 2003; Zhou et al. 2008a). The selection of the appropriate image types depends on the research question to be addressed. For example, medium resolution (e.g. $30 \mathrm{~m}$ ) remotely sensed imagery, such as the most commonly used Landsat Thematic Mapper (TM) or Enhanced Thematic Mapper Plus (ETM+) data, is adequate to map large greenspace such as parks, golf course, and remnant forests. However, most of the patches of urban greenspace (e.g., lawns, street trees, residential yards), as well as their changes, are too small to be detectable by the commonly used $30 \mathrm{~m}$ resolution TM data (Zhou et al. 2008a; Qian et al. 2015a).

These small, but abundant patches of urban greenspace can provide important "local and direct services" such as microclimate regulation, rainwater drainage, and recreational and cultural values (Bolund and Hunhammar 1999; Wu 2014). Without adequate consideration of ecosystem services provided by these urban greenspaces that are too small to be detectable using medium or low spatial resolution images, both the greenspaces and the ecosystem services they provide may virtually "invisible" at worst, and greatly underestimated at best (Pickett 2010; Wu 2014). To adequately characterize the fine-scale heterogeneity of urban greenspace, high resolution imagery is needed (Zhou et al. 2008a; Li et al. 2013).

In this paper, we first briefly review the application of remotely sensed data with different spatial resolution to mapping the amount and change of urban greenspace. Then, using two very well-developed urban districts of Beijing with a long built history, we compare and contrast the changes in urban greenspace based on two different datasets, the most commonly used Landsat TM data with $30 \mathrm{~m}$ resolution, and $2.5 \mathrm{~m}$ high spatial resolution imagery, which is becoming increasingly available. We show that high spatial resolution data are required to adequately quantify the distribution of urban greenspace and its change, and that results from medium-resolution data can be misleading. In the final section, we discuss the importance and necessity of high spatial resolution assessments of urban greenspace for improved understanding on ecosystem services and ecologically and socially sound design and planning.

\section{Pros and cons of low, medium, and high resolution data}

With the advances of remote sensing techniques, there is increasing availability of image data with different spatial resolution for urban greenspace mapping and change analysis (Table 1). These data can be loosely categorized into 3 groups based on their spatial resolution- low, medium and high. Here, we provide an overview of remotely sensed data and their applications in spatiotemporal pattern analysis of urban greenspace.

The most widely used remote sensing data with low spatial resolution include those from the National Oceanic and Atmospheric Administration/Advanced Very High Resolution Radiometer (NOAA/AVHRR), the moderate resolution imaging spectroradiometer (MODIS) and the Systeme Probatoire d'Observation dela Tarre/VEGETATION (SPOT/VGT). Because of the low spatial resolution and wide swath, these datasets are typically used for vegetation analysis at the global, national, and regional scales (Rigina and Rasmussen 2003; Ma et al. 2006; Fensholt et al. 2012). These data, however, are unable to discern the spatial heterogeneity of land cover within the urban areas (Cadenasso et al. 2007; Zhou and Troy 2008). 
Table 1 Applications of remote sensing data with different resolutions in urban greenspace mapping and change analysis

\begin{tabular}{llc}
\hline Data types (spatial resolution) & Example of sensors & Greenspace mapping applications \\
\hline Low & MODIS NOAA-AVHRR & SPOT4-VGT \\
Medium & Landsat TM/ETM+ ASTER & $\begin{array}{c}\text { Vegetation analysis at the global, national, and } \\
\text { regional scales; inadequate for spatiotemporal } \\
\text { pattern analysis of urban greenspace }\end{array}$ \\
High & $\begin{array}{c}\text { Adequate to map relatively large urban greenspace, } \\
\text { such as parks, remnant forests, urban agricultural } \\
\text { fields, and golf courses }\end{array}$ \\
& SPOT 5 IKONOS QUICKBIRD & $\begin{array}{c}\text { Small street trees, lawns, courtyard vegetation, } \\
\text { private gardens and green roofs }\end{array}$ \\
\hline
\end{tabular}

Consequently, such datasets are inadequate for quantifying spatiotemporal pattern of urban greenspace to address many important ecosystem services-related questions.

Medium resolution remote sensing data have been used frequently for urban greenspace mapping and change analysis, in order to understand their ecological and environmental effects (e.g., biodiversity, ecosystem processes, and urban heat islands) (Buyantuyev et al. 2010; Zhou and Wang 2011; Li et al. 2013). Urban greenspace mapped from medium resolution data works well, in general, for relatively large patches (e.g., forest remnants, agricultural fields, and large golf courses). Most of these studies have focused on the dynamics of urban greenspace in a single city or urban region. One of the major findings from such investigations is that changes mostly occurred in the urban-rural periphery, with little change in inner cities (Li et al. 2011; Xu et al. 2011; Zhou and Wang 2011).

Urban greenspace usually is quite dynamic, even in inner cities (Zhou et al. 2008a; Van Den Hoek et al. 2014; Qian et al. 2015b). The lack of changes in inner cities revealed by medium resolution data may be due to the fact that most changes of urban greenspace within built areas tend to be small in size because of their involving individual parcels or design projects (Qian et al. 2015b). Medium resolution data such as the commonly used $30 \mathrm{~m}$ resolution TM data are unable to detect most of these small patches, as well as their changes (Zhou et al. 2008a; Ramos-González 2014; Qian et al. 2015b). However, these small patches of greenspace provide important ecological functions and ecosystem services (Niemelä 2014; Wu 2014).

With the continuous launching of new commercial satellites and advances in aerial photogrammetry, very high-spatial resolution imagery is becoming widely available and affordable. High spatial resolution image data, such as SPOT, IKONOS, and QUICKBIRD, have been increasingly used for fine-scale urban greenspace mapping and change analysis (e.g., Zhou et al. 2008b; MacFaden et al. 2012; RamosGonzález 2014; Qian et al. 2015a). With object-based image analysis approach, patches of small-sized urban greenspace, such as street trees, lawns, and residential yards, can be accurately mapped from high spatial resolution imagery (Mathieu et al. 2007; Zhou and Troy 2008; Zhou et al. 2008b; MacFaden et al. 2012). Fine-scale changes in urban greenspace can also be extracted using multitemporal high spatial resolution image data (e.g., Zhou et al. 2008a; Qian et al. 2015a).

\section{Comparing urban greenspace patterns with high- and medium-resolution data}

Based on the previous section, it is clear that to address ecological and management issues within urban areas, we need to quantify spatiotemporal patterns of urban greenspace with medium- and high-resolution remote sensing data. But what can be gained from high resolution data, and what is lost when using medium resolution data? To address this question, we present a case study

Using Dongcheng and Xicheng, the two oldest urban districts of Beijing as a case study (Fig. 1), we compare and contrast the changes in urban greenspace calculated from medium resolution data $(30 \mathrm{~m})$ and the changes derived from high resolution data $(2.5 \mathrm{~m})$. These two districts are located at the center of Beijing City, with a long and rich development history. Dongcheng and Xicheng districts cover 42 and $51 \mathrm{~km}^{2}$, respectively. As a consequence of population 


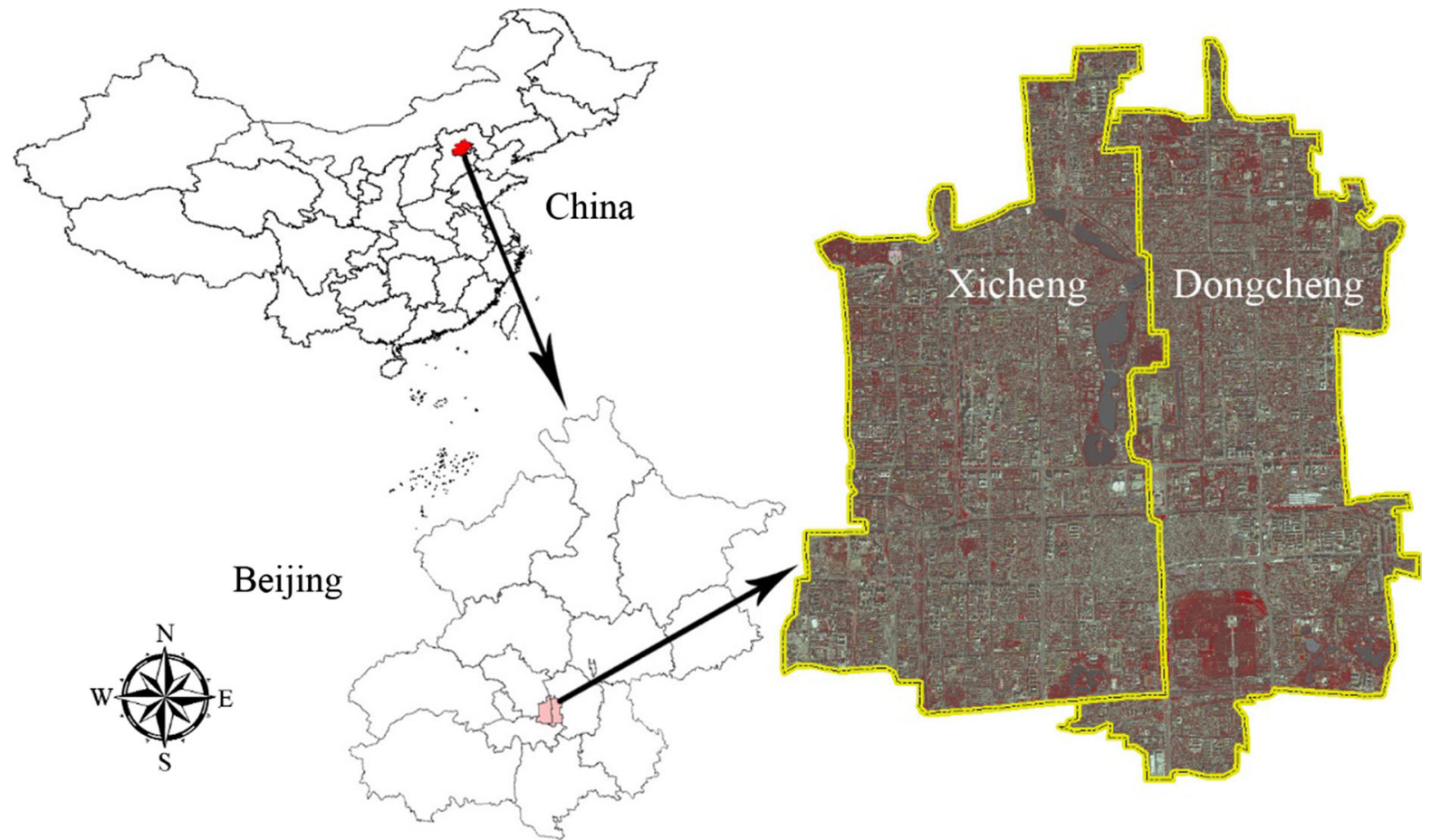

Fig. 1 The location of the study areas: Xicheng and Dongcheng, two highly urbanized districts of Beijing with a very long development history

redistribution within the Beijing metropolitan region, the total population in Dongcheng District decreased slightly from 1.05 million to 0.92 million between 2005 and 2010. Similarly, the total population in Xicheng District decreased slightly from 1.28 million in 2005 to 1.24 million in 2010 .

\section{Mapping urban greenspace}

We mapped urban greenspace, i.e., vegetated areas, using the 4-band pan-sharpened multispectral image data from SPOT-5 and ALOS (Advanced Land Observation Satellite), acquired in October 2005 and October 2009, respectively. The image data have a spatial resolution of $2.5 \mathrm{~m}$, and radiometric depth of 8 bits. We used an object-based approach to extract urban greenspace (Zhou and Troy 2008; Qian et al. 2015b). The land cover classification included four land cover classes: (1) impervious surface, (2) vegetation, (3) water, and (4) bare soil. The overall accuracy of the classification was $92.58 \%$ for 2005 , and $94.12 \%$ for 2009 .
Urban greenspace was also mapped from Landsat-5 TM imagery acquired in summer 2005 and 2009. Landsat-5 TM imagery, with spatial resolution of $30 \mathrm{~m}$, has been the most widely used data for urban greenspace change analysis (e.g. Buyantuyev et al. 2010; Yang et al. 2014). As with the high spatial resolution data, we also used an object-based approach to map urban vegetation from TM imagery. The classification map contained four land cover types: (1) developed land, (2) vegetation, (3) water, and (4) bare soil. The overall accuracies of the classifications were 90.83 and $98.33 \%$ for 2005 and 2009, respectively.

For each urban district, we calculated the percent cover of urban greenspace for both 2005 and 2009. In addition, we calculated several frequently used metrics to quantify the spatial pattern of urban greenspace, including patch density (PD), edge density (ED), mean patch size (MPS) and shape index (SI) of urban greenspace. We did the calculation separately using the two datasets of urban greenspace, and compared the results from the two datasets. We then quantified the changes in the percent cover of greenspace, as well as the other landscape metrics. Furthermore, we 
compared changes from the high spatial resolution dataset with those from the medium resolution one.

\section{Changes in spatial patterns of urban greenspace}

The $30 \mathrm{~m}$ resolution $\mathrm{TM}$ data revealed the percent cover of greenspace in both urban districts to be very low (Fig. 2). In addition, the percent cover of greenspace in both urban districts remained largely unchanged from 2005 to 2009. For example, the percent cover of greenspace in Dongcheng District increased from 7.19 to $7.85 \%$, or an increase of 29.48 ha from 2005 to 2009. Increase of the greenspace coverage in Xicheng District was even less (from 2.57 to $2.77 \%$ ). These results were similar to those found in previous studies conducted in different cities (Xu et al. 2011; Zhou and Wang 2011), which concluded that percent cover of greenspace in well-developed parts of the city is relatively stable, particularly within a short time period.
In contrast, using the $2.5 \mathrm{~m}$ high spatial resolution data, we found the percent cover of greenspace in both urban districts was much higher than that based on the $30 \mathrm{~m}$ resolution TM data (Fig. 2). The percentages of greenspace cover in Dongcheng District were 23.40 and $30.16 \%$ in 2005 and 2009, respectively, in contrast to 7.19 and $7.85 \%$, as suggested by the medium resolution data. Similarly, the percentages of greenspace cover in Xicheng District were 19.10 and $23.73 \%$ in 2005 and 2009, respectively. With the high spatial resolution data, we also found there were significant increases in percent cover of greenspace for both of these dense, old urban districts. The percent cover of greenspace in Dongcheng District increased from 23.40 to $30.16 \%$, an increase of 283.88 ha from 2005 to 2009 , or an annualized increase of 70.97 ha; and from 19.10 to $23.73 \%$ in Xicheng District, an increase of 234.74 ha (Fig. 2).

Similar to our findings for percent cover of greenspace, results for other landscape metrics from

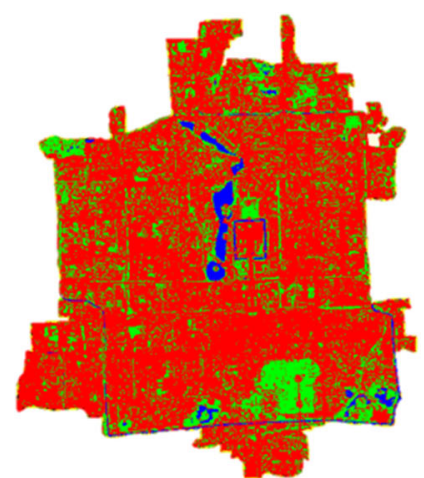

SPOT 2005

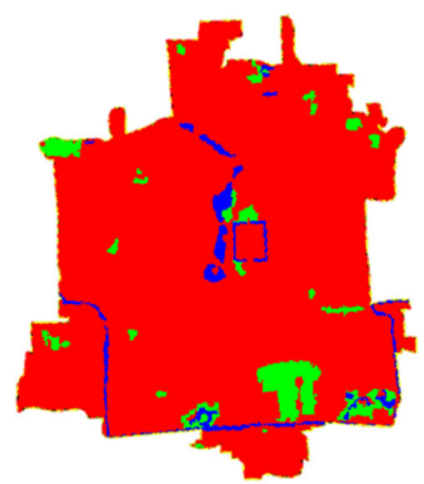

TM 2005

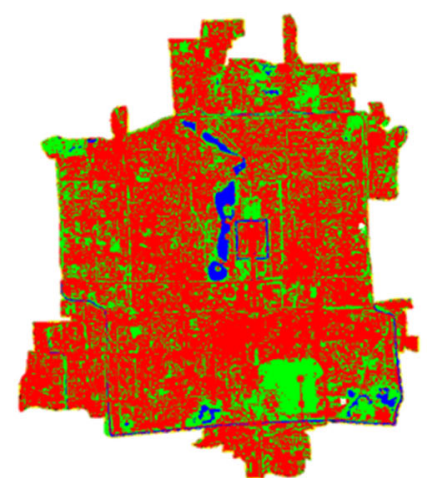

ALOS 2009

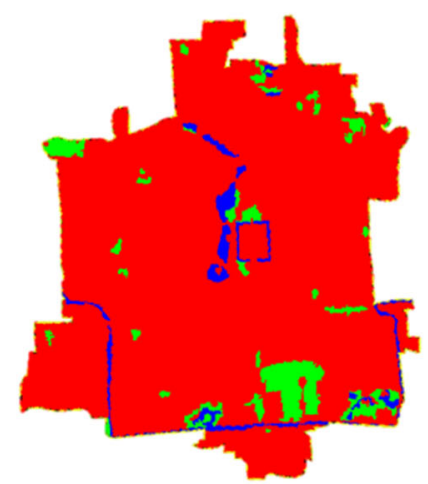

TM 2009

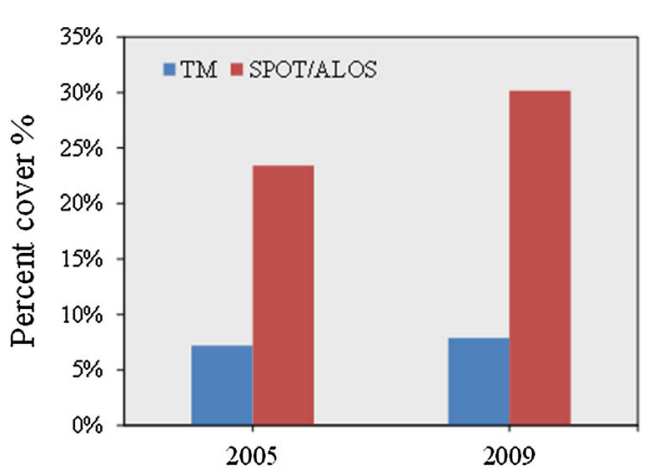

(a) Dongcheng District

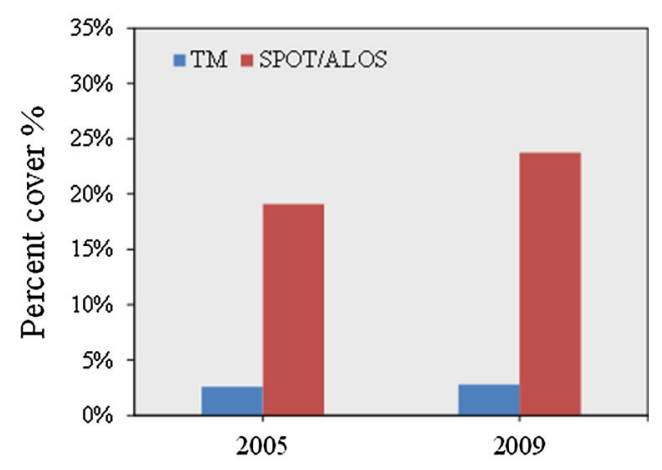

(b) Xicheng District
Fig. 2 Classification results from both high and medium resolution data, where green: urban greenspace; red: impervious surfaces (developed land); blue: water. The two panels on the right show the percent cover of urban greenspace and change mapped from TM and SPOT/ALOS for the two urban districts. (Color figure online) 
Table 2 Spatial patterns of greenspace in Beijing, with highand medium- resolution data

\begin{tabular}{|c|c|c|c|c|}
\hline & \multicolumn{2}{|c|}{ SPOT_2005 (2.5 m) } & \multicolumn{2}{|c|}{ ALOS_2009 $(2.5 \mathrm{~m})$} \\
\hline & Dongcheng & Xicheng & Dongcheng & Xicheng \\
\hline $\mathrm{PD}^{\mathrm{a}}$ & 80.40 & 79.10 & 61.90 & 83.60 \\
\hline $\mathrm{ED}^{\mathrm{b}}$ & 27056.66 & 25037.64 & 26113.45 & 26720.25 \\
\hline $\operatorname{MPS}^{\mathrm{c}}$ & 2910.60 & 2413.74 & 4871.89 & 2839.42 \\
\hline \multirow[t]{3}{*}{$\mathrm{SI}^{\mathrm{d}}$} & 90.59 & 101.95 & 77.01 & 97.60 \\
\hline & \multicolumn{2}{|c|}{ TM_2005 (30 m) } & \multicolumn{2}{|c|}{ TM_2009 (30 m) } \\
\hline & Dongcheng & Xicheng & Dongcheng & Xicheng \\
\hline PD & 0.50 & 0.30 & 0.60 & 0.50 \\
\hline ED & 1045.98 & 534.60 & 1230.16 & 631.82 \\
\hline MPS & 143714.79 & 75389.07 & 132941.66 & 55401.44 \\
\hline SI & 6.47 & 5.53 & 7.28 & 6.30 \\
\hline \multicolumn{5}{|c|}{${ }^{\mathrm{a}}$ Patch density } \\
\hline \multicolumn{5}{|c|}{ b Edge density } \\
\hline \multicolumn{5}{|c|}{ c Mean patch size } \\
\hline d Shap & index & & & \\
\hline
\end{tabular}

the two datasets were very different. For example, patch densities calculated from the high spatial resolution data were much larger than those from the medium resolution data (Table 2), whereas the MPSs were much smaller. This is because patches of urban greenspace with small sizes could not be mapped using the medium resolution data.

Changes in the spatial patterns of greenspace were also different from the two datasets (Table 2). For example, PD decreased from $80.4 / \mathrm{km}^{2}$ in 2005 to $61.9 /$ $\mathrm{km}^{2}$ in 2009 in Dongcheng District based on the high resolution data. But with the TM data, there was a slight increase in PD. Results from the high resolution data indicated that for both districts, the MPS of urban greenspace increased. However, with the TM data, the MPS decreased in Xicheng District.

\section{Discussion}

Why are high spatial resolution data needed for urban greenspace research?

Results from two old, central districts of Beijing indicated that urban greenspace can be highly dynamic, even in very densely built areas. Such dynamics, however, could only be revealed by high spatial resolution imagery. Medium resolution data, such as the most commonly used $30 \mathrm{~m}$ resolution TM data, are unlikely to detect such changes. Our results showed that $30 \mathrm{~m}$ TM data greatly underestimated the percent cover of greenspace. In addition, TM data were not able to detect the significant increases in greenspace coverage that were revealed by the high spatial resolution data.

The highly contradictory results from the two datasets are largely due to the spatial characteristics of urban greenspace and its change. Most of the patches of greenspace in urban areas are too small to be detectable by the $30 \mathrm{~m}$ resolution TM data (Qian et al. 2015a). Additionally, with the very limited space of land available for greening in central districts, many of the new patches of greenspace in highly urbanized areas are likely to be small. Medium resolution data are less likely to detect either the changes at such fine scales, or the increase in tree canopy due to tree growth. Consequently, studies that used medium resolution data tend to find that urban greenspace in inner cities remains largely unchanged over time (e.g., Zhou and Wang 2011). These results underscore the importance of using high resolution imagery in quantifying dynamics of urban greenspace.

Many factors may contribute to the dynamics of urban greenspace in Beijing and other dense, established cities. On the one hand, there are still great pressures from development on conversion of greenspace to buildings because of the very high value of land in the inner city. On the other hand, Beijing has devoted great efforts to increasing urban greenspace, such as the "Plant Where Possible" policy in the urban core of Beijing, and the Million Mu Trees Campaign (one $\mathrm{Mu}$ equals to $1 / 15 \mathrm{ha}$ ), leading to the creation of many of small patches of new urban greenspace. Many other cities in China, as well as in other countries have also implemented similar policies aiming to increase urban greenspace. For example, many cities in the USA have established their Urban Tree Canopy (UTC) goals for tree planting programs, such as the Million Trees Campaign in New York City, and the Million Trees LA in Los Angeles, as a part of their sustainability plans to achieve such benefits as microclimate regulation, stormwater management, and cultural ecosystem services (Nowak 2007; Huang et al. 2011). Urban greenspace at the fine scale in these cities is dynamic, which warrants further 
investigation. Therefore, coarse scale data are inappropriate for assessing greening programs.

Mapping "invisible" urban greenspace for better understanding ecosystem services

Urban greenspace at fine scales plays an essential role in urban ecosystem and contributes greatly to the welfare of urban residents (Niemelä 2014; Wu 2014). Accurate quantification of the spatial pattern and change of urban greenspace is a prerequisite to fully understand ecosystem services provided by urban greenspace. Considering the "invisible" greenspace patches that can only be revealed by high spatial resolution remote sensing data can help better understand and assess ecosystem services provided by urban greenspace.

Similar to large greenspaces such as parks and urban forests, small patches of green cover, such as street trees, residential yards, community gardens, and green roofs, can contribute to biodiversity, stormwater management, microclimate mitigation and other services (Bolund and Hunhammar 1999; Strohbach et al. 2013; Wu 2014; Zhou et al. 2014). Neglected edges of parcels, industrial brownfields, and under-utilized rail and other rights of way are common features in many cities and may contribute to ecosystem services (Pickett 2010). For example, although large greenspaces act as important refuges for wildlife in cities (Donnelly and Marzluff 2004), even small increases of a few hundred square meters in urban greenspace lead to an increase in bird richness (Strohbach et al. 2013). Similarly, increases of urban vegetation, either as small or large patches, decrease land surface temperature (Zhou et al. 2011; Li et al. 2013).

More importantly, unlike large greenspaces that are relatively rare and not within the walking distance for the majority of urban residents (Liu et al. 2014; Wolch et al. 2014), small patches of green cover are embedded in built-up areas (e.g. residential areas) where people live, work, and play. Therefore, while small in size, these green spaces can play crucial roles in providing cultural ecosystem services (Niemelä 2014). Such green spaces can be referred to as "nature nearby" (Nilon 2011). For example, green courtyard gardens in new residential community provide outdoor play spaces for children and teenagers, as well for elderly people (Wolch et al. 2014). Elderly men living in neighborhoods with more green spaces tend to have more participation in regular physical activities (Gong et al. 2014), which is believed important to mental and physical health (Barton and Pretty 2010). Even small amounts of green cover can protect health (Villeneuve et al. 2012). In addition, the frequent interaction between humans and these greenspace patches is believed important for engaging urban residents in conservation effects (Miller and Hobbs 2002).

Incorporating fine-scale urban greenspace characteristics in design and planning

It is widely believed that socially and ecologically sound design and planning are critical for urban sustainability (Wu 2014). There is increasing interest in incorporating ecology and green spaces in urban design and planning to achieve an improved urban sustainability (Wu 2008; Pickett et al. 2013; Niemelä 2014). Spatial pattern and change of urban greenspace at fine scales revealed by high spatial resolution data can provide important insights for urban design and planning. With the very limited amounts of land available for greening, urban designers and planners frequently need fine-scale information to identify where urban greenspace exists, and what areas are potentially available for planting (Troy et al. 2007; Wu et al. 2008; Wu 2010). For example, the relatively fine scale concern of landscape architecture, and of urban design that focuses on individual parcels or projects, can benefit from a refined understanding of the existing distribution of small greenspaces. Fine scale maps of greenspace may suggest opportunities to expand or better connect networks of urban greenspaces, and consequently, enhance the ecosystem services they provide (Forman 2008).

Fine scale data on urban green space is relevant to concerns of environmental justice. That is, racially or ethnically disempowered groups, and low-income people are frequently found to have less access to greenspace than more empowered or more affluent groups (Boone and Fragkias 2012). There is increasing awareness and interest in inequitable access to urban greenspace (Wolf and Housley 2014). To address this environmental injustice issue, urban greenspace design and planning need to better consider not only the social characteristics of the residential areas, but also the fine-scale spatial pattern of urban greenspace.

In addition, as mentioned above, many cities around the world have established goals to increase urban greenspace. Therefore, it is important to 
evaluate the efficacy of their efforts in design, planning and management of urban greenspace. Such evaluation should be based on fine-scale datasets where possible to ensure accuracy of baselines, targets, and assessment of program performance. Taking the Beijing example again, the large number of new small greenspace patches identified by the high spatial resolution reflect the achievements of the "Plant Where Possible" policy. However, this would not be revealed if using the medium resolution data. Urban greenspace design, management and planning should be based on fine-scale datasets to ensure accuracy of baselines, targets, and assessment of the ecosystem services that greenspace provides.

Acknowledgments The support of the National Natural Science Foundation of China (Grant No. 41371197 and 41422104) and the One Hundred Talents program of Chinese Academy of Sciences is gratefully acknowledged. We thank the editor and two anonymous reviewers for their constructive comments, which helped us to improve the manuscript.

\section{References}

Barton J, Pretty J (2010) What is the best dose of nature and green exercise for improving mental health? A multi-study analysis. Environ Sci Technol 44(10):3947-3955

Bolund P, Hunhammar S (1999) Ecosystem services in urban areas. Ecol Econ 29(2):293-301

Boone CG, Fragkias M (2012) Urbanization and sustainability: linking urban ecology, environmental justice and global environmental change. Springer Science \& Business Media, Dordrecht

Buyantuyev A, Wu J, Gries C (2010) Multiscale analysis of the urbanization pattern of the Phoenix metropolitan landscape of USA: time, space and thematic resolution. Landsc Urban Plan 94(3-4):206-217

Cadenasso ML, Pickett STA, Schwarz K (2007) Spatial heterogeneity in urban ecosystems: reconceptualizing land cover and a framework for classification. Front Ecol Environ 5:80-88

Donnelly R, Marzluff JM (2004) Importance of reserve size and landscape context to urban bird conservation. Conserv Biol 18(3):733-745

Fensholt R, Langanke T, Rasmussen K, Reenberg A, Prince SD, Tucker C, Scholes RJ, Le QB, Bondeau A, Eastman R (2012) Greenness in semi-arid areas across the globe 1981-2007 - an earth observing satellite based analysis of trends and drivers. Remote Sens Environ 121(2):144-158

Forman RT (2008) Urban regions: ecology and planning beyond the city. Cambridge University Press, Cambridge

Gong Y, Gallacher J, Palmer S, Fone D (2014) Neighbourhood green space, physical function and participation in physical activities among elderly men: the Caerphilly Prospective study. Int J Behav Nutr Phys Act 11:40. doi:10.1186/14795868-11-40

Home R, Bauer N, Hunziker M (2010) Cultural and Biological Determinants in the Evaluation of Urban Green Spaces. Environ Behav 42(4):494-523

Huang G, Zhou W, Cadenasso M (2011) Is everyone hot in the city? Spatial pattern of land surface temperatures, land cover and neighborhood socioeconomic characteristics in Baltimore MD. J Environ Manag 92(7):1753-1759

Huang Q, Robinson DT, Parker DC (2014) Quantifying spatialtemporal change in land-cover and carbon storage among exurban residential parcels. Landscape Ecol 29(2):275-291

Li M, Zhu Z, Vogelmann JE, Xu D, Wen W, Liu A (2011) Characterizing fragmentation of the collective forests in southern China from multitemporal Landsat imagery: a case study from Kecheng district of Zhejiang province. Appl Geogra 31(3):1026-1035

Li X, Zhou W, Ouyang Z (2013) Relationship between land surface temperature and spatial pattern of greenspace: what are the effects of spatial resolution? Landsc Urban Plan $114: 1-8$

Liu Z, He C, Zhou Y, Wu J (2014) How much of the world's land has been urbanized, really? A hierarchical framework for avoiding confusion. Landscape Ecol 29(5):763-771

Lovell ST, Taylor JR (2013) Supplying urban ecosystem services through multifunctional green infrastructure in the United States. Landscape Ecol 28(8):1447-1463

Ma M, Wang J, Wang X (2006) Advance in the inter-annual variability of vegetation and its relation to climate based on remote sensing. J Remote Sens-Beijing 10(3):421

MacFaden SW, O'Neil-Dunne JP, Royar AR, Lu JW, Rundle AG (2012) High-resolution tree canopy mapping for New York City using LIDAR and object-based image analysis. J Appl Remote Sens 6(1):063567-1-063567-23

Mathieu R, Freeman C, Aryal J (2007) Mapping private gardens in urban areas using object-oriented techniques and very high-resolution satellite imagery. Landsc Urban Plan 81(3):179-192

Miller JR, Hobbs RJ (2002) Conservation where people live and work. Conserv Biol 16(2):330-337

Ng E, Chen L, Wang Y, Yuan C (2012) A study on the cooling effects of greening in a high-density city: an experience from Hong Kong. Build Environ 47:256-271

Niemelä J (2014) Ecology of urban green spaces: the way forward in answering major research questions. Landsc Urban Plan 125:298-303

Nilon CH (2011) Urban biodiversity and the importance of management and conservation. Landscape Ecol Eng $7(1): 45-52$

Nowak DJ (2007) Assessing urban forest effects and values: Philadelphia's urban forest. DIANE Publishing, Philadelphia

Nowak DJ, Crane DE, Stevens JC (2006) Air pollution removal by urban trees and shrubs in the United States. Urban For Urban Green 4(3-4):115-123

Pathak V, Tripathi BD, Mishra VK (2011) Evaluation of anticipated performance INDEX of some tree species for green belt development to mitigate traffic generated noise. Urban For Urban Green 10(1):61-66

Pickett STA (2010) The wild and the city. State of the wild: a global portrait. In: Redford KH, Fearn E (eds) State of the 
wild: a global portrait 2010. Island Press, Washington, pp 153-159

Pickett ST, Cadenasso ML, McGrath B (2013) Resilience in ecology and urban design: linking theory and practice for sustainable cities. Springer Science \& Business Media, Dordrecht

Qian Y, Zhou W, Li W, Han L (2015a) Understanding the dynamic of greenspace in the urbanized area of Beijing based on high resolution satellite images. Urban For Urban Green 14(1):39-47

Qian Y, Zhou W, Yan J, Li W, Han L (2015b) Comparing machine learning classifiers for object-based land cover classification using very high resolution imagery. Remote Sens 7(1):153-168

Ramos-González OM (2014) The green areas of San Juan, Puerto Rico. Ecol Soc 19(3):21

Rigina O, Rasmussen MS (2003) Using trend line and principal component analysis to study vegetation changes in Senegal 1986-1999 from AVHRR NDVI $8 \mathrm{~km}$ data. Geogra Tidsskr-Dan J Geogr 103(1):31-42

Stefanov WL, Ramsey MS, Christensen PR (2001) Monitoring urban land cover change: an expert system approach to land cover classification of semiarid to arid urban centers. Remote Sens Environ 77(2):173-185

Strohbach MW, Lerman SB, Warren PS (2013) Are small greening areas enhancing bird diversity? Insights from community-driven greening projects in Boston. Landsc Urban Plan 114:69-79

Tajima K (2003) New estimates of the demand for urban green space: implications for valuing the environmental benefits of Boston's big dig project. J Urban Aff 25(5):641-655

Thompson CW, Roe J, Aspinall P, Mitchell R, Clow A, Miller D (2012) More green space is linked to less stress in deprived communities: evidence from salivary cortisol patterns. Landsc Urban Plan 105(3):221-229

Troy AR, Grove JM, O’Neil-Dunne JP, Pickett ST, Cadenasso ML (2007) Predicting opportunities for greening and patterns of vegetation on private urban lands. Environ Manage 40(3):394-412

Van Den Hoek J, Ozdogan M, Burnicki A, Zhu AX (2014) Evaluating forest policy implementation effectiveness with a cross-scale remote sensing analysis in a priority conservation area of Southwest China. Appl Geogr 47:177-189

Villeneuve PJ, Jerrett M, Su JG, Burnett RT, Chen H, Wheeler AJ, Goldberg MS (2012) A cohort study relating urban green space with mortality in Ontario, Canada. Environ Res 115:51-58

Wolch JR, Byrne J, Newell JP (2014) Urban green space, public health, and environmental justice: the challenge of making cities 'just green enough'. Landsc Urban Plan 125:234-244

Wolf KL, Housley E (2014) Environmental equality: providing nearby nature for everyone. TKF Foundation, Annapolis

Wu JG (2008) Toward a landscape ecology of cities: beyond buildings, trees, and urban forests. In: Carreiro MM, Song
YC, Wu JG (eds) Ecology, planning and management of urban forests: international perspectives. Springer, New York, pp 10-28

Wu J (2010) Urban sustainability: an inevitable goal of landscape research. Landscape Ecol 25(1):1-4

Wu J (2013) Landscape sustainability science: ecosystem services and human well-being in changing landscapes. Landscape Ecol 28(6):999-1023

Wu J (2014) Urban ecology and sustainability: the state-of-thescience and future directions. Landsc Urban Plan 125:209221

Wu C, Xiao Q, McPherson EG (2008) A method for locating potential tree-planting sites in urban areas: a case study of Los Angeles, USA. Urban For Urban Green 7(2):65-76

Xu X, Duan X, Sun H, Sun Q (2011) Green space changes and planning in the capital region of China. Environ Manag 47(3):456-467

Yang J, McBride J, Zhou J, Sun Z (2005) The urban forest in Beijing and its role in air pollution reduction. Urban For Urban Green 3(2):65-78

Yang J, Huang CH, Zhang ZY, Wang L (2014) The temporal trend of urban green coverage in major Chinese cities between 1990 and 2010. Urban For Urban Green 13(1):19-27

Zhang X, Friedl MA, Schaaf CB, Strahler AH, Hodges JCF, Gao F, Reed BC, Huete A (2003) Monitoring vegetation phenology using MODIS. Remote Sens Environ 84(3):471475

Zhou W, Troy A (2008) An object-oriented approach for analysing and characterizing urban landscape at the parcel level. Int J Remote Sens 29(11):3119-3135

Zhou X, Wang Y (2011) Spatial-temporal dynamics of urban green space in response to rapid urbanization and greening policies. Landsc Urban Plan 100(3):268-277

Zhou W, Troy A, Grove M (2008a) Object-based land cover classification and change analysis in the Baltimore metropolitan area using multitemporal high resolution remote sensing data. Sensors 8(3):1613-1636

Zhou W, Troy A, Grove M (2008b) Modeling residential lawn fertilization practices: integrating high resolution remote sensing with socioeconomic data. Environ Manag 41(5): $742-752$

Zhou W, Huang G, Cadenasso ML (2011a) Does spatial configuration matter? Understanding the effects of land cover pattern on land surface temperature in urban landscapes. Landsc Urban Plan 102(1):54-63

Zhou W, Huang G, Pickett STA, Cadenasso ML (2011b) 90 years of forest cover change in an urbanizing watershed: spatial and temporal dynamics. Landscape Ecol 26:645-659

Zhou W, Qian Y, Li X, Li W, Han L (2014) Relationships between land cover and the surface urban heat island: seasonal variability and effects of spatial and thematic resolution of land cover data on predicting land surface temperatures. Landscape Ecol 29(1):153-167 